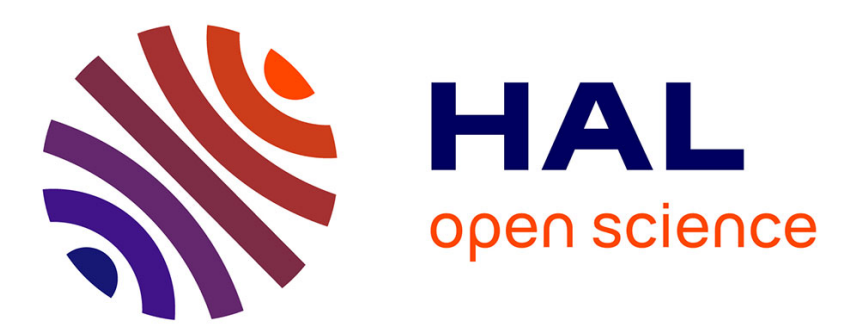

\title{
Electro-reductive deiodination of iohexol catalyzed by vitamin B12 and biodegradability investigation
}

W. Zhang, I. Soutrel, Abdeltif Amrane, F. Fourcade, Florence Geneste

\section{To cite this version:}

W. Zhang, I. Soutrel, Abdeltif Amrane, F. Fourcade, Florence Geneste. Electro-reductive deiodination of iohexol catalyzed by vitamin B12 and biodegradability investigation. Journal of Electroanalytical Chemistry, 2021, 897, pp.115559. 10.1016/j.jelechem.2021.115559 . hal-03335277

\section{HAL Id: hal-03335277 \\ https://hal.science/hal-03335277}

Submitted on 15 Sep 2021

HAL is a multi-disciplinary open access archive for the deposit and dissemination of scientific research documents, whether they are published or not. The documents may come from teaching and research institutions in France or abroad, or from public or private research centers.
L'archive ouverte pluridisciplinaire HAL, est destinée au dépôt et à la diffusion de documents scientifiques de niveau recherche, publiés ou non, émanant des établissements d'enseignement et de recherche français ou étrangers, des laboratoires publics ou privés. 


\title{
Electro-reductive deiodination of iohexol catalyzed by vitamin B12 and biodegradability investigation
}

Wei Zhang $^{\mathrm{a}, \mathrm{b}}$, Isabelle Soutrel ${ }^{\mathrm{b}}$, Abdeltif Amrane ${ }^{\mathrm{b}}$, Florence Fourcade ${ }^{\mathrm{b} *}$, Florence Geneste $^{\mathrm{c}^{*}}$

aUniv Rennes, CNRS, ISCR-UMR 6226, F-35000 Rennes, France

bUniv Rennes, Ecole Nationale Supérieure de Chimie de Rennes, CNRS, ISCR-UMR 6226, F-35000 Rennes, France

\begin{abstract}
Owing to their high consumption for X-ray diagnose and to their rapid excretion from organism, iodinated X-ray contrast media (ICM) are often found in source waters. It is a serious public health concern due to their potential to generate highly toxic disinfection by-products. Reductive deiodination of ICM is considered as a promising approach to degrade them and allows the possible recovery of iodide ions. Electrocatalytic reduction of iohexol, an ionic ICM, was performed in the presence of vitamin B12 as catalyst. Vitamin B12 was chosen owing to its catalytic activity toward dehalogenation processes and to its positive effect on biodegradation of pollutants. The
\end{abstract}

* Correspondence: Dr Florence Geneste, Florence.geneste@univ-rennes1.fr and Dr Florence Fourcade, Florence.fourcade@univ-rennes1.fr 
conditions for electrocatalysis were optimized to favor the electrocatalytic process over the direct reduction, leading to the enhancement of the reaction kinetic and the current efficiency. A total deiodination of iohexol was achieved after 1h of electrolysis. A biological treatment with activated sludge underlined a low decrease of the dissolved organic carbon even after electroreduction. However, the concentration of iohexol decreased and a significant biotransformation of iohexol occurred, slightly improved by the presence of vitamin B12. The identification of the main by-products after the biotransformation of iohexol highlighted the oxidation of the primary and secondary alcohols of the alkyl chains.

Keywords. X-ray contrast media, deiodination, vitamin B12, electrocatalysis, biological treatment, biodegradability

\section{Introduction}

Human medicine and especially medical imaging is a major consumer of tri-iodized organic compounds used as X-ray contrast agents [1, 2]. As they are injected in human body in large dose and completely excreted after around 24h [1, 2], iodinated X-ray contrast media (ICM) are detected in hospital effluent and then in domestic sewage system $[3,4]$.

Biological treatments are not efficient to treat such organic compounds because of their particular molecular structure and their low biodegradability [5-7]. Moreover, it has been shown that ICM can be transformed into toxic by-products during drinking water disinfection [8]. 
Due to the risk of accumulation in the environment, the scientific community is looking for efficient treatments of ICM polluted effluents. Among physicochemical processes, advanced oxidation processes showed their efficiency but the formation of toxic intermediates has been reported for incomplete mineralizations [9-13]. Reductive deiodination processes, especially electroreduction, are very promising because ICM are easy to reduce and hard to oxidize [14-18]. In addition, electroreduction can be considered as a green technique to remove halogenated pollutants since extra reducing agents are not needed. Furthermore, it is also considered as an economic and effective approach owing to its high selectivity [19-25].

Electrocatalytic dehalogenation by metallic nanoparticles and transition metal complex catalysts have become a research hotspot since the presence of catalyst could shorten reaction time and improve current efficiency. For example, the exceptional electrocatalytic behavior of micro- and nano- Ag particles has been illustrated for $\mathrm{CHCl}_{3}$ detoxification from gaseous flow [26]. Lou and co-workers have also shown that deschloroalachlor, the dechlorinated derivative of alachlor, was obtained with a yield of $72 \%$ when the electroreduction of alachlor was performed on silver nanoparticles deposited on a nickel-coated graphite felt against only $40 \%$ on the $\mathrm{Ni}$ graphite felt electrode without silver [24]. Likewise, Yang and co-workers have deposited palladium on nickel foam electrode to electrodechlorinate florfenicol, and have shown a dechlorination rate 6.3 times higher than the rate obtained with nickel foam electrode alone [27]. Transition metal complex catalysts have also shown very high selectivity and high current efficiency for the catalytic dehalogenation of pollutants. For example, Fontmorin et al. have shown that the dechlorination of 1,3dichloropropane using $\mathrm{Ni}(\mathrm{tmc}) \mathrm{Br}_{2}$ complex as catalyst led to an almost total dechlorination, whereas no reaction occurred in the absence of catalyst [19]. 
Interestingly, in the presence of coordination complexes as catalysts, the reduction of the carbon-halogen bonds of pollutants is highly selective and can be performed at relatively high potential, minimizing the competition with hydrogen evolution and improving the current efficiency [28]. To the best of our knowledge, there is no literature relative to the electrocatalytic deiodination of ICM by transition metal complex catalysts. The scission of carbon-iodine bonds is effectively more accessible compared with the cleavage of carbon-chlorine bonds. However, electrocatalytic deiodination of ICM could be envisaged to achieve rapid removal rates and high current efficiencies that are inevitable challenges for efficient environment treatments, decreasing the electricity consumption and so the cost of the electrochemical process.

Vitamin $\mathrm{B}_{12}$ is a biological cobalt complex known as cyanocobalamin (Scheme 1), which is based on a corrin skeleton with four reduced pyrrole rings joined into a macrocyclic ring [29]. Over the years, vitamin $\mathrm{B}_{12}$ has been extensively used in nonelectrochemical catalytic dehalogenation [30-34] and in electrocatalytic dehalogenation [35-37].

Interestingly, some literatures have pointed out that cyanocobalamin could improve the rate of carbon tetrachloride degradation by specific anaerobic bacteria in pure cultures Acetobacterium woodii [38] and by anaerobic microbial enrichment [39]. It has been also demonstrated that the presence of cyanocobalamin improves the dechlorination of hexachloro-1,3-butadiene to nonchlorinated gases by activated sludge bacteria [40].

We have previously shown that the removal of carbon-iodide bond improved the biodegradability of diatrizoate, a highly biorecalcitrant ICM [18]. The coupling of an electrocatalytic reduction process with a cost-effective biological treatment for the total mineralization of ICM is particularly interesting since it would also allow the recovery 
of iodide ions in the industrial process. Owing to its high catalytic ability to cut carbonhalogen bonds and to its properties to enhance biodegradation of halogenated compounds by bacteria, vitamin B12 appeared as a good candidate for the coupling of electrocatalytic reduction of ICM with a biological treatment. In this work, the electrocatalytic activity of vitamin B12 was studied for the deiodination of iohexol (Scheme 1), a typical ionic ICM, followed by a biological treatment with activated sludge. The electrocatalytic activity of vitamin B12 toward the reduction of iohexol was first studied and the conditions for the electrolysis optimized to achieve a total deiodination of iohexol with improved current efficiency. Then, the biodegradability of the electrolyzed solution was tested in a biological treatment with activated sludge.

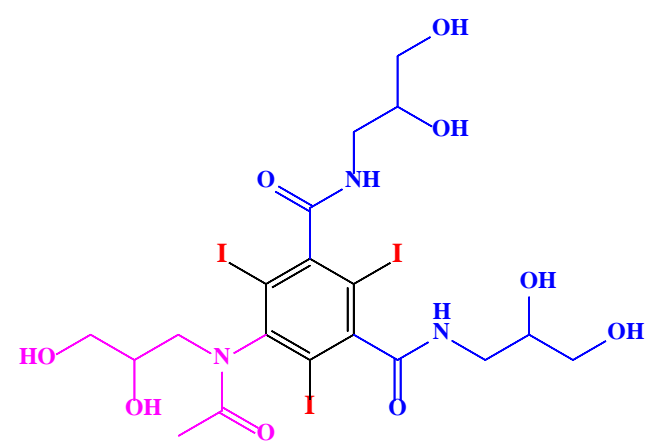

Iohexol

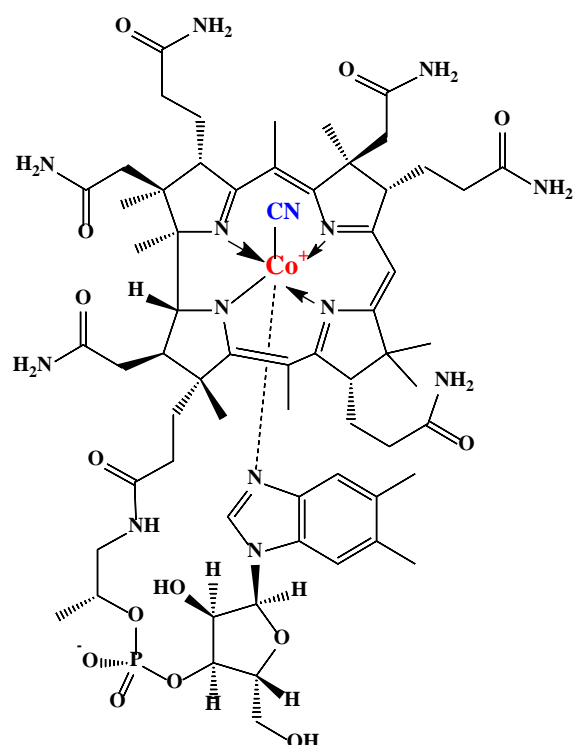

Vitamin $\mathrm{B}_{12}$ (cyanocobalamin)

Scheme 1. Structures of iohexol and vitamin B12 


\section{Materials and Methods}

\subsection{Chemicals and Materials}

Anhydrous sodium sulfate $\left(\mathrm{Na}_{2} \mathrm{SO}_{4}\right) 99 \%$, iohexol, cyanocobalamin (vitamin $\mathrm{B}_{12}$ ), potassium iodine (KI) were purchased from Sigma-Aldrich (France). Graphite felt (GF, Recycled vein graphite RVG 4000) was obtain from Mersen (France). Dimensionally stable anodes (DSA), AC-2004, were supplied by ECS International Electro Chemical Services, France.

\subsection{Electrocatalytic system}

The electrochemical flow cell [41] was constructed with two equal ring-shaped Perspex frames with internal diameter $4.8 \mathrm{~cm}$ and thickness $1.6 \mathrm{~cm}$. A cation exchange membrane (Nafion ${ }^{\mathrm{TM}}$ 417, France) was inserted in the middle of two glue-sealed single frames. Two unit frames, two counter electrodes (DSA) and a working electrode (graphite felt diameter $4.8 \mathrm{~cm}$ and thickness $1.0 \mathrm{~cm}$ ) were bolted together between two plastic plates. The total empty volumes for cathodic and anodic compartments were both $29 \mathrm{~mL}$. Before use, graphite felt was dipped in ethanol, and then rinsed with deionized water to eliminate ethanol. The working electrode, counter electrode and reference electrode were connected through a potentiostat (VersaSTAT 3 from Elancourt, France). The electrolytic solution flowed through the graphite felt with recycling.

2.3. Cyclic voltammetry analysis (CV) 
$\mathrm{CV}$ analyses were performed with an EDAQ potentiostat unit equipped with the ECchem software package. The electrochemical experiments were implemented in a typical three electrodes system with a saturated calomel electrode (SCE) as the reference electrode, a platinum plate as a counter electrode and a glassy carbon $(\mathrm{d}=0.25$ $\mathrm{cm})$ as the working electrode. The working electrode was carefully polished with sand paper (European \# P4000, Struers, Ballerup, Denmark) and rinsed with distilled water before each run. All experiments were conducted in argon saturated solutions at room temperature. The electrolyte was $0.1 \mathrm{~mol} \mathrm{~L}^{-1} \mathrm{Na}_{2} \mathrm{SO}_{4}$ adjusted if necessary to $\mathrm{pH} 3$ and 11 with $\mathrm{H}_{2} \mathrm{SO}_{4}$ and $\mathrm{NaOH}$, respectively.

\subsection{HPLC analysis}

The residual concentration of iohexol was quantified by high performance liquid chromatography (HPLC). Before analysis, samples were filtered through a $0.2 \mu \mathrm{m}$ membrane filter. The HPLC system consisted of a Waters 996 High Performance Liquid Chromatography equipped with a Waters 996 PDA (Photodiode Array Detector) and a Waters 600 LCD Pump. The separation was conducted on a column Waters C-18 (5 $\mu \mathrm{m}$; $4.6 \times 250 \mathrm{~mm}$ ). Ten microliters of sample were injected with an auto-sampler. The carrier liquid consisted of a solution A composed of 95\% of deionized water and 5\% acetonitrile as well as $0.1 \%$ formic acid, and a solution B composed of acetonitrile containing $0.1 \%$ formic acid. The gradient elution is A $100 \%$ B $0 \%$ for 2 minutes then A 0\% B 100\% in 6 minutes and for 2 minutes, finally A 100\% B 0\% in 1 minute at a flow rate of $0.4 \mathrm{~mL} \mathrm{~min}{ }^{-1}$. Iohexol was detected at a wavelength of $243 \mathrm{~nm}$ at a column temperature of $35^{\circ} \mathrm{C}$. 


\subsection{Silver rotating disc electrode for iodide ions analysis}

The concentration of released $\mathrm{I}^{-}$during electrocatalytic reduction of iohexol was measured by linear sweep analysis with a silver rotating disc electrode (Fig. 1) [42]. The analysis was performed in a three-electrode system with a saturated calomel electrode (SCE) as the reference electrode, a platinum wire as a counter electrode and a silver rotating disc electrode $(\mathrm{d}=0.5 \mathrm{~cm})$ as a working electrode. The rotating speed was fixed at $1000 \mathrm{rpm}$ for the $\mathrm{I}^{-}$detection experiments. First, a calibration curve was plotted with different concentrations of $\mathrm{KI}$ in $0.1 \mathrm{~mol} \mathrm{~L}^{-1} \mathrm{Na}_{2} \mathrm{SO}_{4}(\mathrm{pH}=7)$.
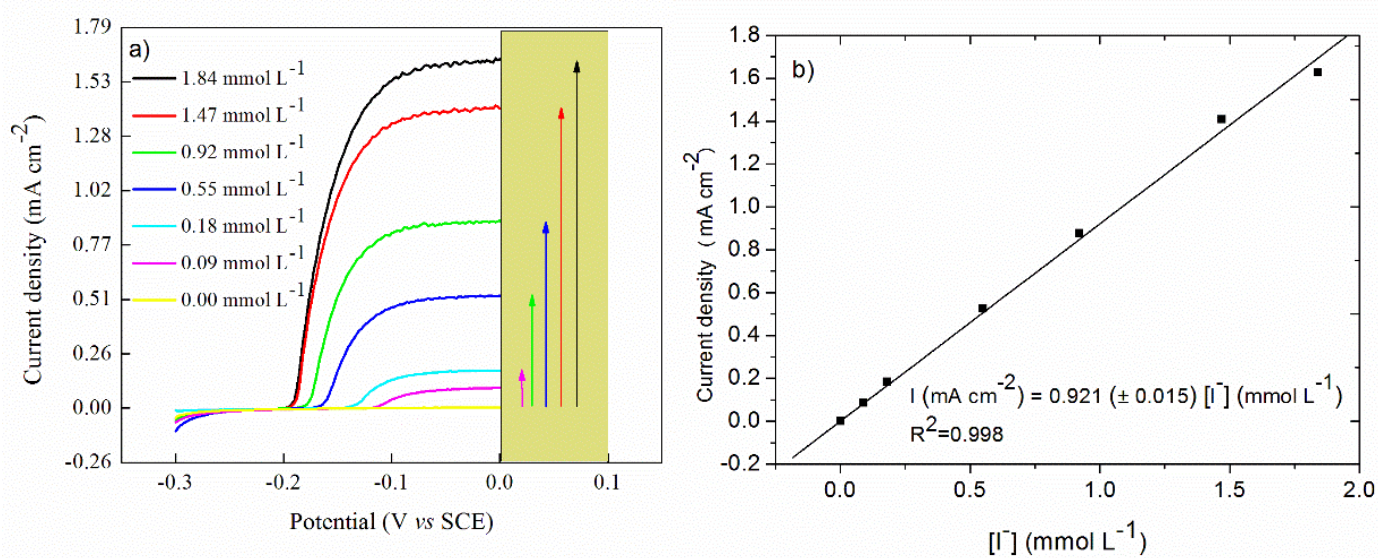

Fig. 1. a) Linear sweep voltammogram at a silver rotating disc electrode $\left(0.20 \mathrm{~cm}^{2}\right)$ of different concentrations of KI, scan rate: $20 \mathrm{mV} \mathrm{s}^{-1}$, rotating speed: $1000 \mathrm{rpm}$. Potential range: - $300-100 \mathrm{mV}$ b) Calibration curve

The curve was linear in the studied range of 0.09 to $1.84 \mathrm{mmol} \mathrm{L}^{-1}$ with a correlation coefficient of 0.998 and can be expressed according to the following equation:

$\Delta \mathrm{Ip}(\mathrm{mA})=0.921( \pm 0.015)\left[\mathrm{I}^{-}\right]\left(\mathrm{mmol} \mathrm{L}^{-1}\right)$ 
DOC was measured after filtration at $0.22 \mu \mathrm{m}$ by means of TOC-VCPH/CPN Total Organic Analyzer Schimadzu as previously reported [43].

\subsection{Chemical Oxygen Demand (COD) measurements}

Chemical Oxygen Demand (COD) was measured by means of Nanocolor ${ }^{\circledR}$ tests CSB 160 and 1500 from Macherey-Nagel (Düren, Germany). The amount of oxygen required for the oxidation of the organic and mineral matter at $148^{\circ} \mathrm{C}$ for $2 \mathrm{~h}$ was quantified after oxidation with $\mathrm{K}_{2} \mathrm{Cr}_{2} \mathrm{O}_{7}$.

\subsection{Biodegradability evaluation}

The biodegradability was evaluated by the ratio of Biological Oxygen Demand in 5 days $\left(\mathrm{BOD}_{5}\right)$ to Chemical Oxygen Demand (COD), which was performed in an incubator box set at a temperature of $20^{\circ} \mathrm{C}$. The biodegradability of iohexol and of the by-products after electrolysis was determined. Activated sludge, taken from the Beaurade wastewater treatment plant (Rennes, France), was considered. Before treatment, activated sludge had to be washed 8-10 times with tap water to remove the dissolved organic matter. For $\mathrm{BOD}_{5}$ test, samples were added in $500 \mathrm{~mL}$ brown bottles containing the culture medium with orbital shaking (300 rpm). The composition of the $\mathrm{BOD}_{5}$ culture medium was: $\mathrm{MgSO}_{4} \cdot 7 \mathrm{H}_{2} \mathrm{O}, \mathrm{CaCl}_{2}, \mathrm{FeCl}_{3} \cdot 6 \mathrm{H}_{2} \mathrm{O}, \mathrm{NH}_{4} \mathrm{Cl}, \mathrm{KH}_{2} \mathrm{PO}_{4}$, $\mathrm{K}_{2} \mathrm{HPO}_{4}$ at concentrations of $22.5,27.5,0.15,2.0,6.8,2.8 \mathrm{~g} \mathrm{~L}^{-1}$, respectively. The concentration of activated sludge was $0.05 \mathrm{~g} \mathrm{~L}^{-1}$. All samples were adjusted to $\mathrm{pH} 7$ before $\mathrm{BOD}_{5}$ measurement and at least duplicated. Then bottles were closed with sensor caps, which automatically recorded each hour the $\mathrm{BOD}_{5}$ value.

\section{Results and discussion}



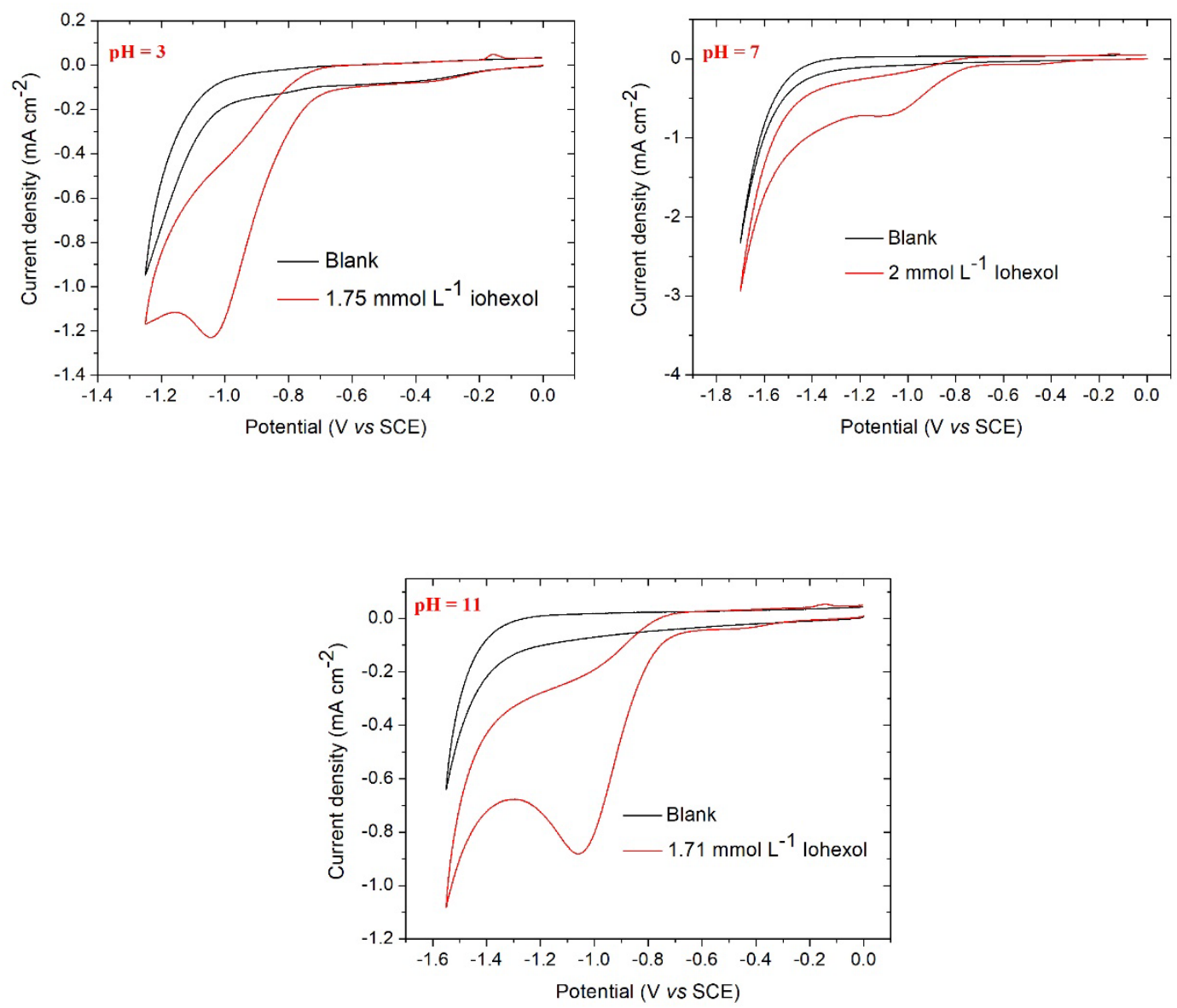

Fig. 2. Cyclic voltammograms in $0.1 \mathrm{~mol} \mathrm{~L}^{-1} \mathrm{Na}_{2} \mathrm{SO}_{4}$ without (-) (blank) and with (-) iohexol at $\mathrm{pH} \mathrm{3,} \mathrm{7,} \mathrm{11.} \mathrm{Scan} \mathrm{rate:} 20 \mathrm{mV} \mathrm{s}^{-1}$.

The electroactivity of iohexol was first checked by cyclic voltammetry analysis on a glassy carbon electrode in $0.1 \mathrm{~mol} \mathrm{~L}^{-1} \mathrm{Na}_{2} \mathrm{SO}_{4}$ at $\mathrm{pH} 3,7$ and 11 to check the effect of pH on its electroactivity. As displayed in Fig. 2, a reduction peak was observed at a potential around $-1.0 \mathrm{~V}$ vs SCE with an onset potential around $-0.76 \mathrm{~V}$ vs SCE for all studied media. The first step of the reduction process, which involves a one-electron reduction with a carbon-halogen bond breaking (Eq. 1) is known as the rate-determining step [44]. 
$R X+e^{-} \rightarrow R^{+}+X^{-}$

Eq. 1

It would explain that the potential of the irreversible peak observed in cyclic voltammetry was not $\mathrm{pH}$ dependent.
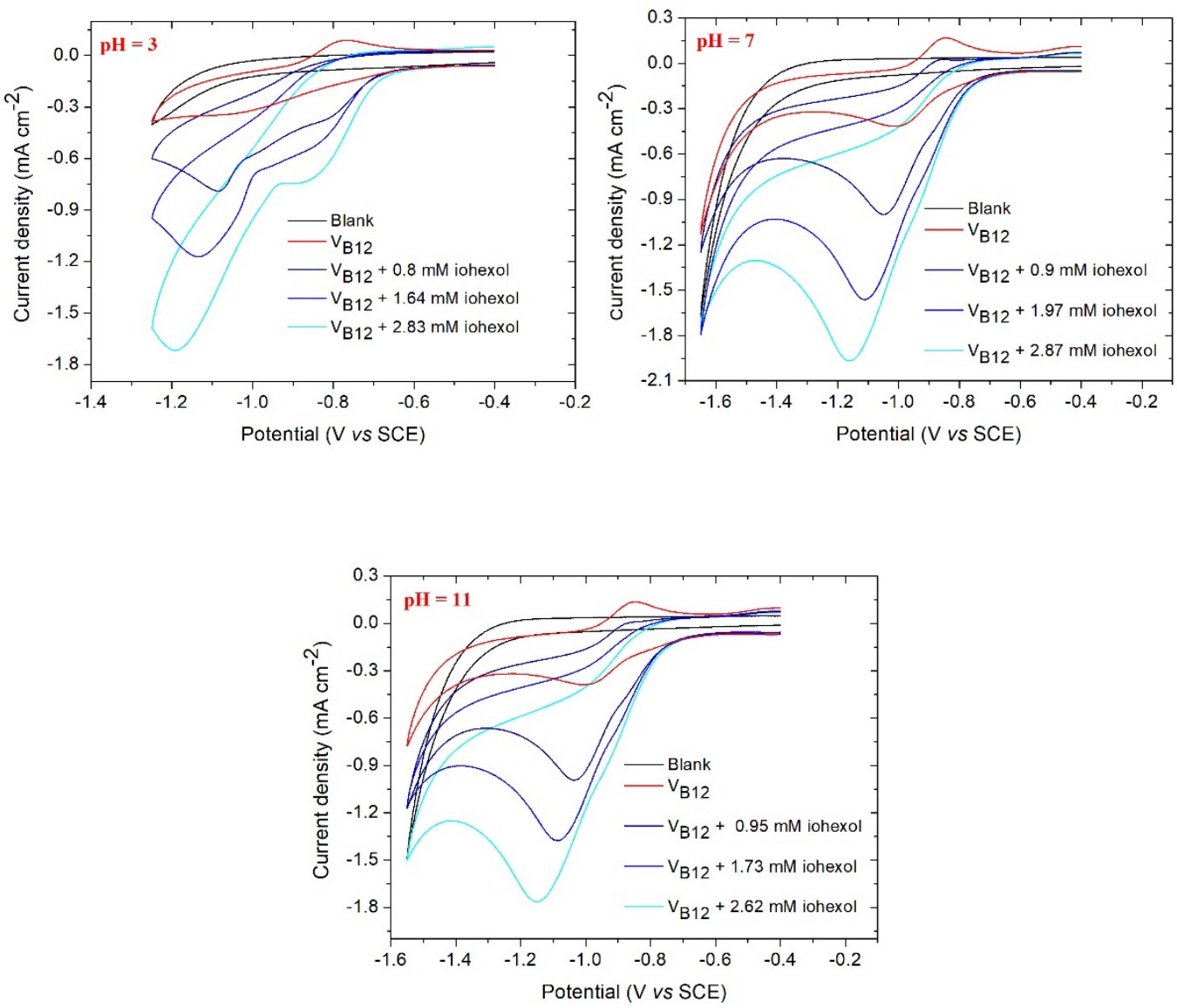

Fig. 3. Cyclic voltammograms of $2 \mathrm{mmol} \mathrm{L}^{-1}$ vitamin $\mathrm{B} 12\left(\mathrm{~V}_{\mathrm{B} 12}\right)$ in $0.1 \mathrm{~mol} \mathrm{~L}^{-1} \mathrm{Na}_{2} \mathrm{SO}_{4}$ + different concentrations of iohexol at $\mathrm{pH}$ 3, 7, 11 (first scan). Blank: cyclic voltammetry in $0.1 \mathrm{~mol} \mathrm{~L}^{-1} \mathrm{Na}_{2} \mathrm{SO}_{4}$. Scan rate: $20 \mathrm{mV} \mathrm{s}^{-1}$.

To check the electrocatalytic activity of vitamin $\mathrm{B} 12$ at different $\mathrm{pH}$, cyclic voltammetry analyses were performed in the presence of different concentrations of iohexol in $0.1 \mathrm{~mol} \mathrm{~L}^{-1} \mathrm{Na}_{2} \mathrm{SO}_{4}$ at $\mathrm{pH}$ 3, 7 and 11 (Fig. 3). The electrochemical behavior 
of vitamin B12 has been well studied [45-47]. The 2-electron wave of the first scan corresponds to the one-electron reduction of $\mathrm{Co}(\mathrm{III})$ accompanied by $\mathrm{CN}^{-}$cleavage, and the reduction of $\mathrm{Co}(\mathrm{II})$ into $\mathrm{Co}(\mathrm{I})$ that occurs at the same potential. The anodic peak is due to the oxidation of $\mathrm{Co}(\mathrm{I})$ into $\mathrm{Co}(\mathrm{II})$, whereas the oxidation of $\mathrm{Co}(\mathrm{II})$ into $\mathrm{Co}(\mathrm{III})$ happens at a less negative potential $(-0.4 \mathrm{~V}$ vs SCE) [35, 48]. The mechanism of the catalytic dehalogenation of bromo and chloro compounds in aqueous medium by vitamin B12 has been well studied and is given in Scheme 2 [49-51]. Co(I) complex reacts with the halogenated substrate to give the cobalt(III) complex, which is reduced into a cobalt(II) complex. It has been also reported that the presence of a protic solvent is essential for a high efficiency of the catalysis [51]. Thus, after addition of iohexol, the cathodic peak at -1.1 V vs SCE increased due to the continuous formation of Co(II), whereas the anodic peak decreased, since Co(I) rapidly reacted with iohexol (Scheme 2). The disappearance of the anodic peak and the slight increase of the cathodic peak compared with the reduction current of iohexol at the same concentration (Fig. 2) are in favor of an electrocatalytic activity of Co(I) toward the reduction of iohexol [20].

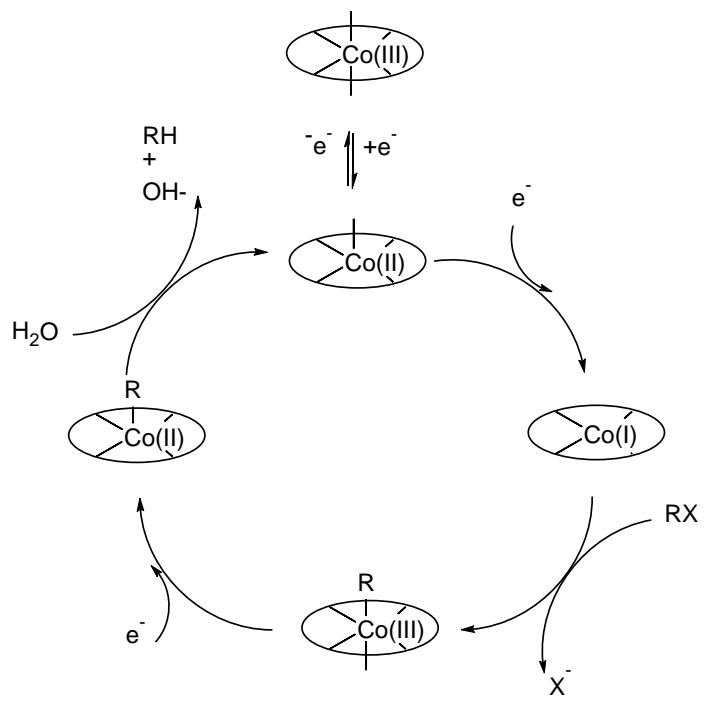


Scheme 2. Mechanism of dehalogenation reaction catalyzed by vitamin B12 in aqueous medium [51].

However, this reaction is in competition with the direct reduction of iohexol as outlined by the presence of a peak (or shoulder) around $-0.9 \mathrm{~V}$ vs SCE. This peak is well-defined at $\mathrm{pH} 3$ and appeared as a shoulder at $\mathrm{pH} 7$ and 11 . Since the biological treatment is performed at $\mathrm{pH}$ 7, this $\mathrm{pH}$ was considered for the electrocatalysis of iohexol.

\subsection{Electrocatalytic deiodination process}

The electrocatalytic reduction of $0.5 \mathrm{mmol} \mathrm{L}^{-1}$ iohexol in a $0.5 \mathrm{~mol} \mathrm{~L}^{-1} \mathrm{pH}=7$ phosphate buffer solution $\left(\mathrm{NaH}_{2} \mathrm{PO}_{4} 0.25 \mathrm{M}\right.$; $\left.\mathrm{Na}_{2} \mathrm{HPO}_{4} 0.25 \mathrm{M}\right)$ was carried out in a flow electrochemical cell with vitamin B12 as catalyst. The experimental conditions (catalyst/iohexol ratio and applied potential) were first optimized.

\subsubsection{Optimization of the catalyst/iohexol ratio}

The electrochemical reduction of $0.5 \mathrm{mmol} \mathrm{L}^{-1}$ iohexol was first performed in the presence of vitamin B12 at concentrations ranging from 10 to $100 \mu \mathrm{mol} \mathrm{L}-1$ (Fig. 4). 


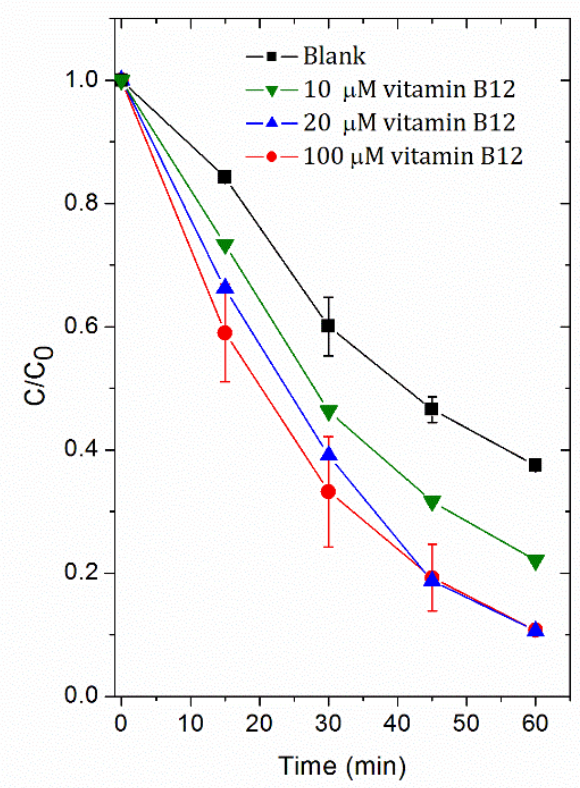

Fig. 4. Ratio of iohexol concentration to the initial one versus time for electrolysis of $0.5 \mathrm{mmol} \mathrm{L} \mathrm{L}^{-1}$ iohexol in a $0.5 \mathrm{~mol} \mathrm{~L}^{-1} \mathrm{pH}=7$ phosphate buffer solution performed at $0.8 \mathrm{~V}$ vs SCE. Error bars are based on duplicate experiments.

Although direct reduction of iohexol already occurred at the potential used for the electroreduction (-0.8 V vs SCE) as observed by cyclic voltammetry, the reaction was faster in the presence of vitamin B12. The reaction rate increased with the concentration of catalyst, leading to $67 \%$ of iohexol reduction after only 30 min of reaction with 100 $\mu \mathrm{mol} \mathrm{L} \mathrm{L}^{-1}$ vitamin B12. This concentration of catalyst was used for next experiments.

\subsubsection{Optimization of the potential}

The catalytic reduction of $0.5 \mathrm{mmol} \mathrm{L}^{-1}$ iohexol in a $0.5 \mathrm{~mol} \mathrm{~L}^{-1} \mathrm{pH}=7$ phosphate buffer solution with $100 \mu \mathrm{mol} \mathrm{L}{ }^{-1}$ vitamin B12 was performed at different potentials ranging from -0.6 to -1.1 V vs SCE. A blank (iohexol without catalyst) was made in the same conditions for comparison. Iohexol concentration was measured by HPLC (Fig. 5) and 
iodide ions were analyzed by linear sweep voltammetry (LSV) on a silver rotating disc electrode (Fig. 6). The yields of released I' was calculated according to the formula of Eq. 2:

Yield $=\frac{C_{I^{-}}}{3 \times C_{\text {iohexol }}}$

Where $C_{I^{-}}$is the concentration of $\mathrm{I}^{-}$detected by linear sweep voltammetry, $C_{\text {iohexol }}$ is the initial molar concentration of iohexol.
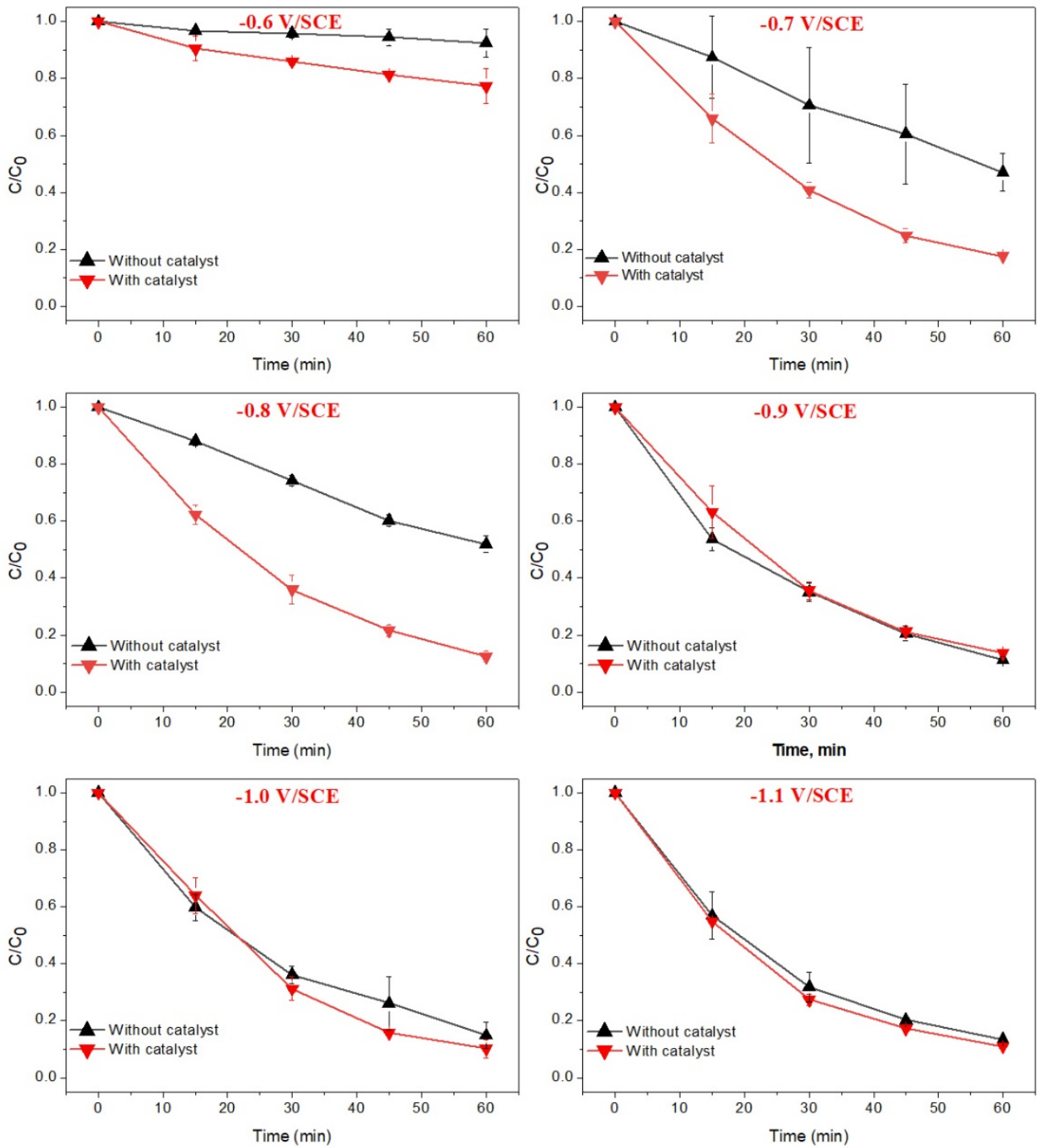
Fig. 5. Removal efficiency of iohexol with and without catalyst for 1h electroreduction for potentials ranging from $-0.6 \mathrm{~V}$ to $-1.1 \mathrm{~V} v s \mathrm{SCE}\left(0.5 \mathrm{mmol} \mathrm{L}{ }^{-1}\right.$ iohexol in a $0.5 \mathrm{~mol}$ $\mathrm{L}^{-1} \mathrm{pH}=7$ phosphate buffer solution with $100 \mu \mathrm{mol} \mathrm{L} \mathrm{L}^{-1}$ vitamin B12). Error bars are based on duplicate experiments.
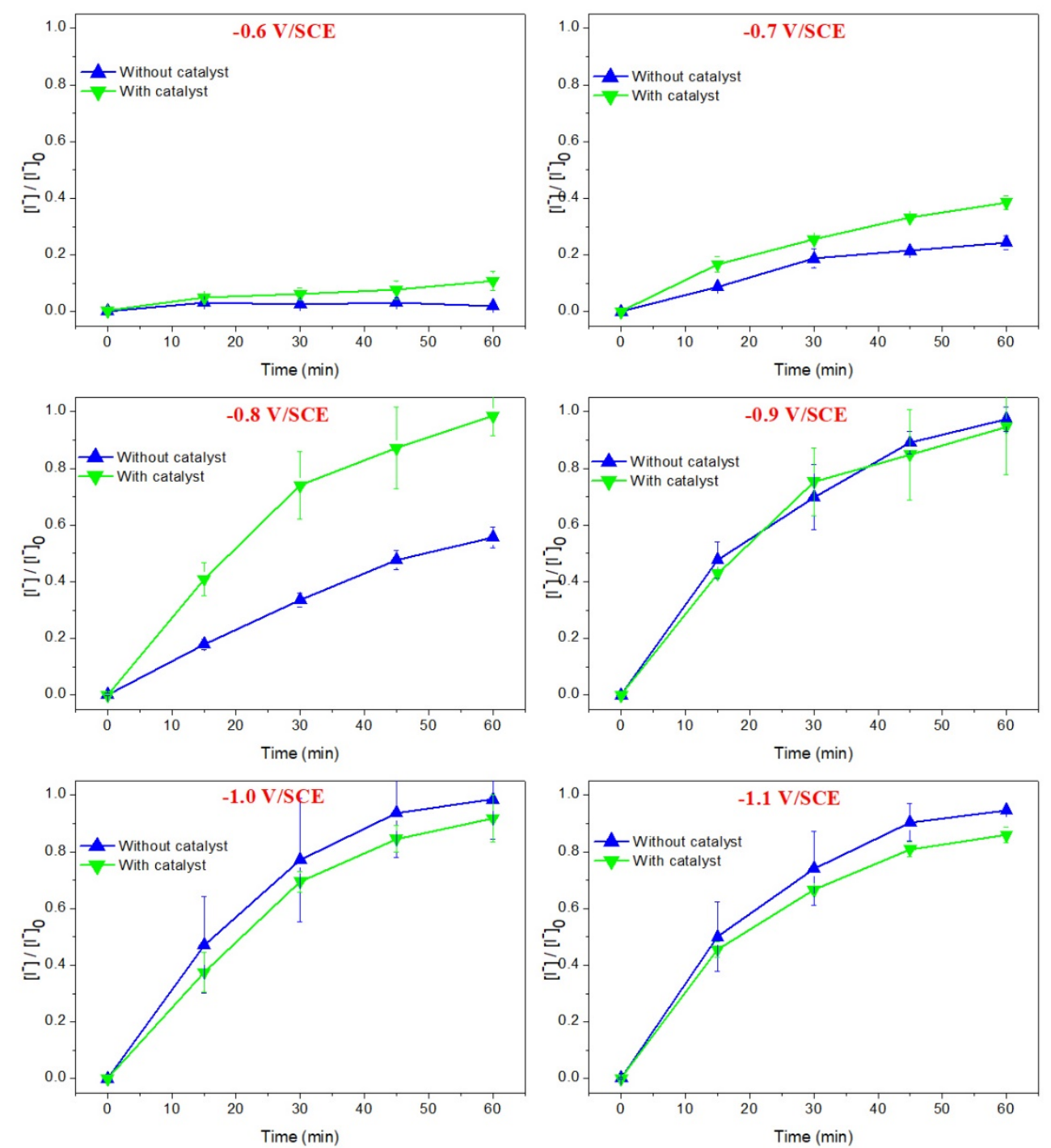

Fig. 6. Yield of released iodine considering the three iodine atoms with and without catalyst during $1 \mathrm{~h}$ electroreduction at potentials ranging from $-0.6 \mathrm{~V}$ to $-1.1 \mathrm{~V}$ vs SCE. (0.5 mmol L ${ }^{-1}$ iohexol in a $0.5 \mathrm{~mol} \mathrm{~L}^{-1} \mathrm{pH}=7$ phosphate buffer solution with $100 \mu \mathrm{mol}$ $\mathrm{L}^{-1}$ vitamin B12). Error bars are based on duplicate experiments. 
We checked the validity of the LSV method by comparing the results with ion chromatography for iohexol electrolyses performed at $-1.1 \mathrm{~V}$ vs SCE. Similar concentrations (standard deviation $<0.05 \mathrm{mmol} \mathrm{L}^{-1}$ ) were obtained, although the LSV analytical method was chosen, since it allowed a fast, accurate and in situ analysis of iodide ions concentration.

The comparison with the blank showed that the reaction was faster in the presence of vitamin B12 for potentials between -0.6 and $-0.8 \mathrm{~V}$ vs SCE. However, for potentials higher than $-0.9 \mathrm{~V} v$ s SCE, the effect of catalyst on the results was not obvious. At -0.8 V vs SCE, a 88\% decrease of iohexol was observed after 1h of electrolysis, which was relatively consistent with the dehalogenation yield (98\%) calculated from the concentration of remaining iodide ions. However, at $-0.7 \mathrm{~V}$ vs SCE, although the decrease of iohexol was good (82\%), the dehalogenation yield was only $38 \%$. This result tends to show that a partial reduction of iohexol occurred at $-0.7 \mathrm{~V}$ vs SCE, leading to iodinated intermediates.

The current efficiency (CE) corresponding to the deiodination of iohexol after $1 \mathrm{~h}$ of electrolysis was calculated according to Eq. 3 for all studied potentials.

$\mathrm{CE}=\frac{\mathrm{C}_{\mathrm{I}^{-}} \times n_{e} \times \mathrm{F} \times \mathrm{V}}{\mathrm{Q}}$ Eq. 3

Where $\mathrm{CI}_{\mathrm{I}}^{-}$is the concentration of released $\mathrm{I}^{-}$after 1 h electrolysis, $\mathrm{F}$ is Faraday constant, $\mathrm{V}$ is the volume of iohexol, $n_{e}$ is the number of electrons and $\mathrm{Q}$ is the experimental charge for 1 h electrolysis.

The current efficiencies are given in Fig. 7. 


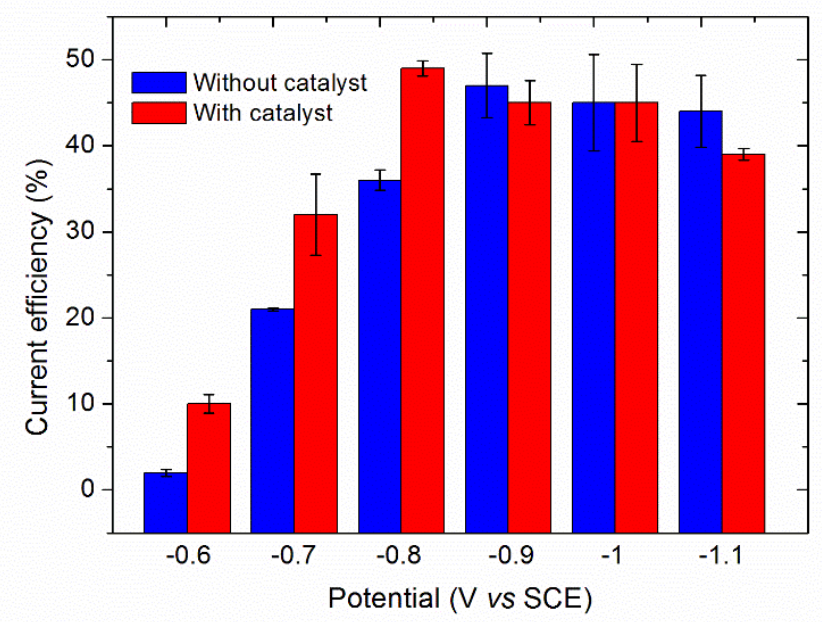

Fig. 7. Current efficiency of iohexol deiodination with and without catalyst after $1 \mathrm{~h}$ electroreduction for potentials ranging from $-0.6 \mathrm{~V}$ to $-1.1 \mathrm{~V}$ vs SCE. $\left(0.5 \mathrm{mmol} \mathrm{L}^{-1}\right.$ iohexol in a $0.5 \mathrm{~mol} \mathrm{~L}{ }^{-1} \mathrm{pH}=7$ phosphate buffer solution with $100 \mu \mathrm{mol} \mathrm{L}{ }^{-1}$ vitamin B12). Error bars are based on duplicate experiments.

The current efficiencies were clearly improved by the presence of catalyst for potentials between -0.6 and $-0.8 \mathrm{~V}$ vs SCE, reaching a maximum value of $49 \%$ at $-0.8 \mathrm{~V}$ vs SCE. This is due to the higher deiodination yield obtained with the catalyst, especially at -0.8 V vs SCE. It is important to underline that the residual current (probably due to sidereactions such as residual dioxygen reduction) affected the current efficiencies since the concentration of iohexol was low. When the experimental charge corresponding to the blank (i.e. electrolysis performed in the same conditions at -0.8 V/SCE but without iohexol and catalyst, around $18 \mathrm{C}$ ) was subtracted from the charge measured after $1 \mathrm{~h}$ of electroreduction (around 40.5 C), a current efficiency of 88\% was obtained. Since at this potential a competition with hydrogen evolution is unlikely, the residual charge could be decreased by the optimization of the flow cell. Furthermore, the analysis of by-products by UPLC-MS/MS show the presence of unidentified peaks in addition to the peak corresponding to dehalogenated iohexol (molecular mass $\mathrm{MH}^{+}$of 444). The 
formation of other reduction products could also affect the current efficiency. For potentials higher than $-0.9 \mathrm{~V} / \mathrm{SCE}$, the current efficiency of electroreductions performed with and without catalyst are identical, confirming that direct electroreduction is predominant.

The turnover number of catalyst was calculated from the following equation:

$T O=\frac{3 \times n_{I^{-}}}{n_{\text {cat }}}$ Eq. 4

Where $n_{I^{-}}$is the number of moles of released iodide ions and $n_{\text {cat }}$ is the number of moles of vitamin B12.

A turnover number around 14 was calculated for electroreduction performed at -0.8 V/SCE after $1 \mathrm{~h}$ of catalysis. This value is low since a high concentration of catalyst is necessary to favor catalytic electroreduction over direct reduction of iohexol.

\subsection{Biodegradability evaluation}

The biodegradability of the solution after electrochemical treatment was first evaluated by the $\mathrm{BOD}_{5} / \mathrm{COD}$ ratio. Thus, $0.25 \mathrm{mmol} \mathrm{L}^{-1}$ iohexol in a $0.1 \mathrm{~mol} \mathrm{~L}^{-1} \mathrm{Na}_{2} \mathrm{SO}_{4}$, without or with $20 \mu \mathrm{mol} \mathrm{L} \mathrm{L}^{-1}$ vitamin B12 was electroreduced at $-1 \mathrm{~V} / \mathrm{SCE}$ to allow a total removal of iohexol and a total dehalogenation after $1 \mathrm{~h}$ of electrolysis even without catalyst. Sodium sulfate was used instead of phosphate buffer to avoid an excess of phosphorus during the biological treatment that could affect bacteria. 


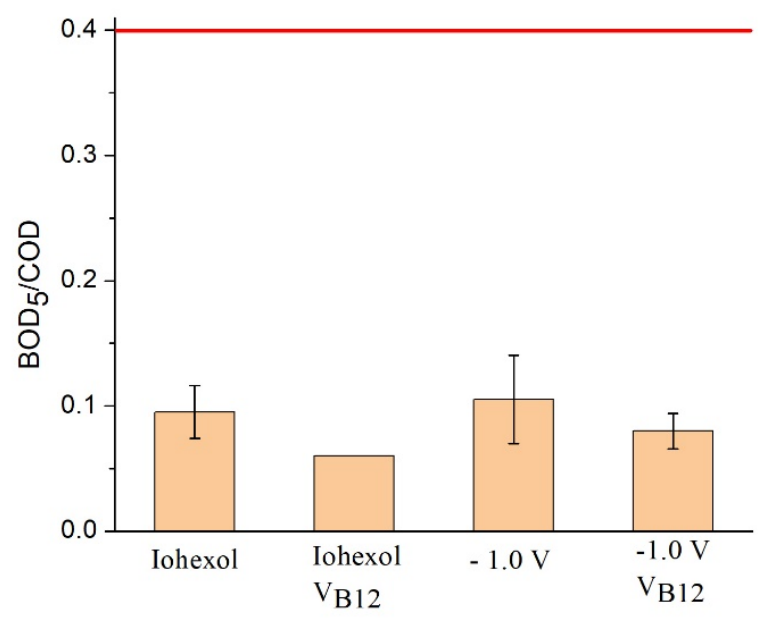

Fig. 8. $\mathrm{BOD}_{5} / \mathrm{COD}$ ratio of iohexol before and after electrochemical treatment with or without vitamin B12 ( $\left.\mathrm{V}_{\mathrm{B} 12}\right)$. Error bars are based on duplicate experiments. Red line: the threshold value for a solution to be biodegradable

Iohexol was not biodegradable as outlined by the $\mathrm{BOD}_{5} / \mathrm{COD}$ value (around 0.1 ) that was significantly lower than 0.4 , the threshold value usually admitted for a solution to be biodegradable (Fig. 8). The addition of $20 \mu \mathrm{mol} \mathrm{L}{ }^{-1}$ vitamin B12 did not improve the biodegradability. Furthermore, after electrolysis with or without vitamin B12, the solution was still not biodegradable. To confirm these results, a biological treatment of the solutions by activated sludge was then performed over a period of 21 days. The biodegradation of the solutions was monitored by DOC measurement (Fig. 9). Results were consistent with the biodegradability estimated by the $\mathrm{BOD}_{5} / \mathrm{COD}$ ratio since the mineralization yield was still very low (around 10-20\%) after 21 days. In opposite with previous results obtained with diatrizoate [18], the dehalogenation of iohexol did not improve its biodegradability. For a better understanding of the biodegradation mechanism, the concentrations of iohexol and of released iodide ions were monitored during its biological treatment with and without vitamin B12 (Fig. 10). A decrease of 
the iohexol concentration was observed with a biotransformation of $48 \%$ for iohexol and $70 \%$ in the presence of vitamin B12. As previously observed in literature [38-40], vitamin B12 increased the biotransformation of iohexol, even if the resulting byproducts were still recalcitrant. An increase of iodide ions concentration also occurred during the biological treatment (Fig. 10b), although it corresponded to non-significant dehalogenation yields (3-4\%). The mechanism of iohexol biotransformation did not seem to mainly involve a dehalogenation process. Further analyses by UPLC-MS/MS of iohexol after the biological treatment showed the apparition of three main compounds with molecular mass $\left(\mathrm{MH}^{+}\right)$of $863.8,833.8$ and 861.8 (Table 1). It corresponds to the oxidation of the primary and secondary alcohols as previously reported for iohexol and iopamidol [52]. The stability of these main by-products observed even after 21 days of biological treatment can explain the low biodegradability of the solution.

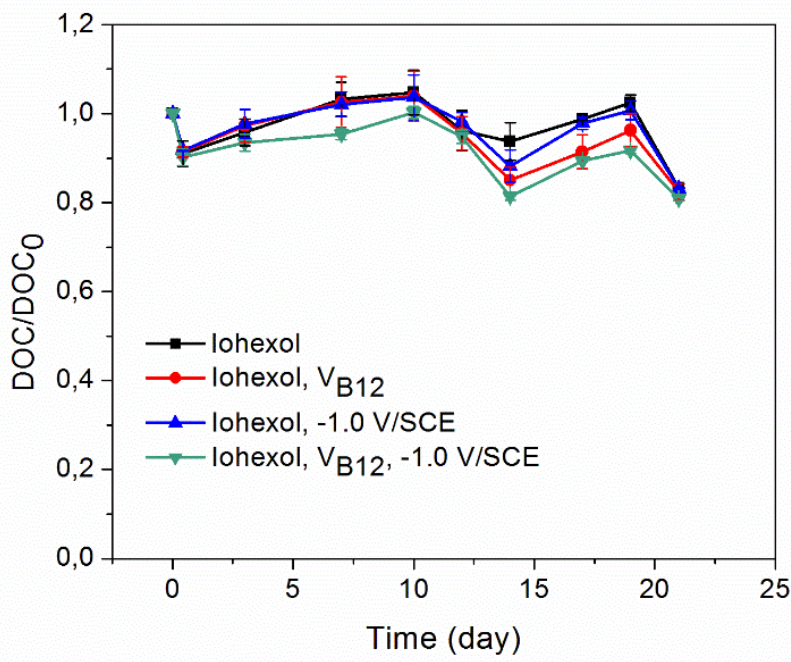

Fig. 9. Time-courses of DOC values during activated sludge culture on iohexol solution before and after electrochemical treatments. Error bars are based on duplicate experiments. 

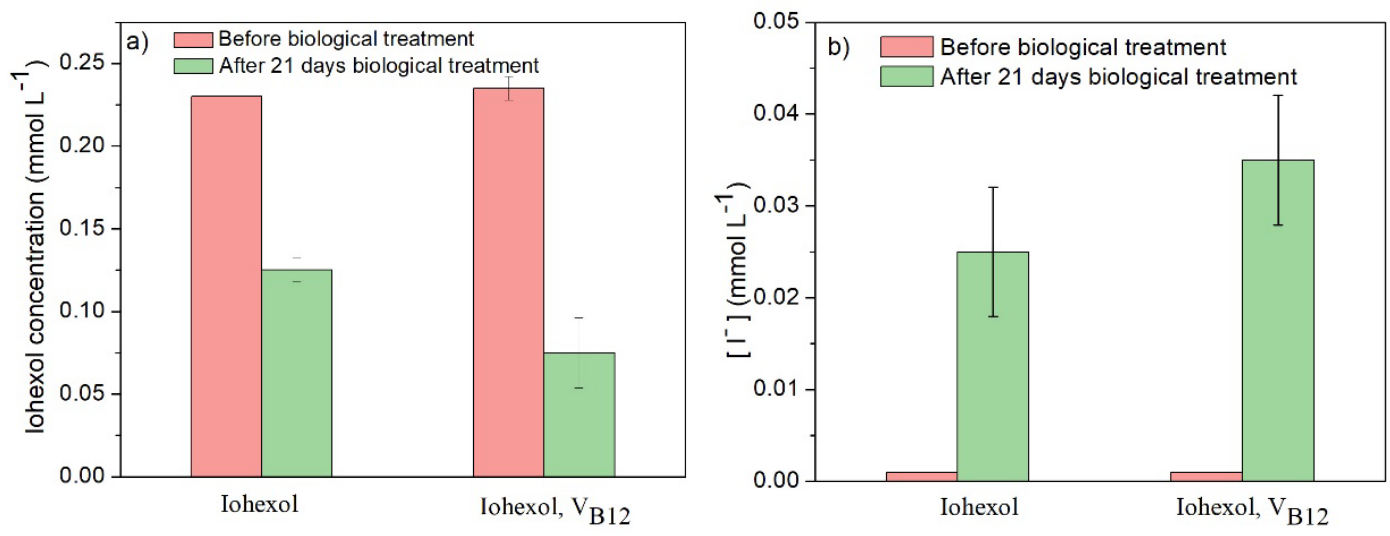

Fig. 10. a) Iohexol concentration and b) iodide ions concentration before and after the biological treatment. Error bars are based on duplicate experiments.

Table 1. LC-MS/MS identification of main by-products for biotransformation of Iohexol.

\begin{tabular}{|l|l|l|l|l|}
\hline Time (min) & $\mathrm{m} / \mathrm{z}$ & Structure & $863.79\left(\mathrm{H}^{+}\right)$ & \\
\hline 1.2 and 1.3 & $885.71\left(\mathrm{Na}^{+}\right)$ & $853.79\left(\mathrm{Na}^{+}\right)$ &
\end{tabular}




\begin{tabular}{|l|l|l}
8.0 and 1.1 & $861.77\left(\mathrm{H}^{+}\right)$ \\
$883.78\left(\mathrm{Na}^{+}\right)$ &
\end{tabular}

\section{Conclusions}

The catalytic activity of vitamin B12 for electroreductive deiodination of iohexol was first demonstrated by cyclic voltammetry analyses. The electrocatalytic conditions (i. e. iohexol/vitamin B12 ratio and applied potentials) were optimized to favor the electrocatalytic process over the direct reduction. Vitamin B12 increased the kinetic of the reaction and improved the current efficiency. A total dehalogenation of iohexol was thus achieved with a current efficiency of $49 \%$ in only 1 h of electroreduction at $-0.8 \mathrm{~V}$ vs SCE. This result is particularly interesting for the recovery of iodide ions. The turnover number (14) was low due to the high concentration of catalyst that is necessary to favor the indirect process. These results should be improved by the immobilization of the catalyst on the electrode. Indeed, it would allow a high concentration of catalyst on the electrode surface preventing direct electroreduction. Furthermore, a higher turnover number would be expected since it has been previously shown that the immobilization of catalysts improved their stability [21, 53]. The biorecalcitrance of iohexol and of the electroreduced solution was estimated by a biological treatment. A non-significant mineralization yield was obtained after 21 days of incubation. However, a high biotransformation of iohexol (70\%) was observed that seems to be slightly enhanced by the presence of vitamin B12. The mechanism of iohexol biodegradation was not due to a dehalogenation reaction since the deiodination yield was insignificant 
(3-4\%). HPLC-MS/MS analyses of by-products after 21 days of biological treatment showed that iohexol undergoes a biotransformation by oxidation of the primary and secondary alcohols, leading to relatively stable compounds. It would explain the low mineralization yield obtained even after the deiodination process.

\section{Acknowledgements}

The authors thank the China Scholarship Council (CSC) for a Ph.D. grant.

\section{References}

[1] K.G. Estep, K.A. Josef, E.R. Bacon, C.R. Illig, J.L. Toner, D. Mishra, W.F. Blazak, D.M. Miller, D.K. Johnson, J.M. Allen, 1, 3, 5-Trialkyl-2, 4, 6-triiodobenzenes: Novel X-ray contrast agents for gastrointestinal imaging, J. Med. Chem., 43 (2000) 1940-1948. [2] S.-B. Yu, A.D. Watson, Metal-based X-ray contrast media, Chem. Rev., 99 (1999) 2353-2378.

[3] L.F. Delgado, P. Charles, K. Glucina, C. Morlay, QSAR-like models: a potential tool for the selection of PhACs and EDCs for monitoring purposes in drinking water treatment systems-a review, Water Res., 46 (2012) 6196-6209.

[4] J.L. Kormos, M. Schulz, T.A. Ternes, Occurrence of iodinated X-ray contrast media and their biotransformation products in the urban water cycle, Environ. Sci. Technol., 45 (2011) 8723-8732.

[5] A. Haiß, K. Kümmerer, Biodegradability of the X-ray contrast compound diatrizoic acid, identification of aerobic degradation products and effects against sewage sludge micro-organisms, Chemosphere, 62 (2006) 294-302.

[6] J.L. Kormos, M. Schulz, H.-P.E. Kohler, T.A. Ternes, Biotransformation of selected 
iodinated X-ray contrast media and characterization of microbial transformation pathways, Environ. Sci. Technol., 44 (2010) 4998-5007.

[7] M. Redeker, A. Wick, B.r. Meermann, T.A. Ternes, Removal of the iodinated Xray contrast medium diatrizoate by anaerobic transformation, Environ. Sci. Technol., 48 (2014) 10145-10154.

[8] C.H. Jeong, E.J. Machek, M. Shakeri, S.E. Duirk, T.A. Ternes, S.D. Richardson, E.D. Wagner, M.J. Plewa, The impact of iodinated X-ray contrast agents on formation and toxicity of disinfection by-products in drinking water, J. Environ. Sci., 58 (2017) 173-182.

[9] M.M. Huber, A. GÖbel, A. Joss, N. Hermann, D. LÖffler, C.S. McArdell, A. Ried, H. Siegrist, T.A. Ternes, U. von Gunten, Oxidation of pharmaceuticals during ozonation of municipal wastewater effluents: a pilot study, Environ. Sci. Technol., 39 (2005) 4290-4299.

[10] X. Duan, X. He, D. Wang, S.P. Mezyk, S.C. Otto, R. Marfil-Vega, M.A. Mills, D.D. Dionysiou, Decomposition of iodinated pharmaceuticals by UV-254 nm-assisted advanced oxidation processes, J. Hazard. Mater., 323 (2017) 489-499.

[11] L. Zhou, C. Ferronato, J.-M. Chovelon, M. Sleiman, C. Richard, Investigations of diatrizoate degradation by photo-activated persulfate, Chem. Eng. J., 311 (2017) 28-36. [12] R. Banaschik, H. Jablonowski, P.J. Bednarski, J.F. Kolb, Degradation and intermediates of diclofenac as instructive example for decomposition of recalcitrant pharmaceuticals by hydroxyl radicals generated with pulsed corona plasma in water, J. Hazard. Mater., 342 (2018) 651-660.

[13] C.-Y. Hu, Y.-Z. Hou, Y.-L. Lin, A.-P. Li, Y.-G. Deng, Degradation kinetics of diatrizoate during UV photolysis and UV/chlorination, Chem. Eng. J., 360 (2019) 10031010. 
[14] C. Zwiener, T. Glauner, J. Sturm, M. Wörner, F.H. Frimmel, Electrochemical reduction of the iodinated contrast medium iomeprol: iodine mass balance and identification of transformation products, Anal. Bioanal. Chem., 395 (2009) 1885.

[15] M. Stieber, A. Putschew, M. Jekel, Treatment of pharmaceuticals and diagnostic agents using zero-valent iron-kinetic studies and assessment of transformation products assay, Environ. Sci. Technol., 45 (2011) 4944-4950.

[16] J. Radjenovic, V. Flexer, B.C. Donose, D.L. Sedlak, J. Keller, Removal of the Xray contrast media diatrizoate by electrochemical reduction and oxidation, Environ. Sci. Technol., 47 (2013) 13686-13694.

[17] M. Yan, Z. Chen, N. Li, Y. Zhou, C. Zhang, G. Korshin, Electrochemical reductive dehalogenation of iodine-containing contrast agent pharmaceuticals: Examination of reactions of diatrizoate and iopamidol using the method of rotating ring-disc electrode (RRDE), Water Res., 136 (2018) 104-111.

[18] W. Zhang, I. Soutrel, A. Amrane, F. Fourcade, F. Geneste, Electrochemical Processes Coupled to a Biological Treatment for the Removal of Iodinated X-ray Contrast Media Compounds, Front. Chem., 8 (2020) 646.

[19] J.-M. Fontmorin, W. He, D. Floner, F. Fourcade, A. Amrane, F. Geneste, Reductive dehalogenation of 1, 3-dichloropropane by a [Ni (tetramethylcyclam)] $\mathrm{Br}_{2}-$ Nafion ${ }^{\circledR}$ modified electrode, Electrochim. Acta, 137 (2014) 511-517.

[20] W. He, J.-M. Fontmorin, P. Hapiot, I. Soutrel, D. Floner, F. Fourcade, A. Amrane, F. Geneste, A new bipyridyl cobalt complex for reductive dechlorination of pesticides, Electrochim. Acta, 207 (2016) 313-320.

[21] W. He, J.-M. Fontmorin, I. Soutrel, D. Floner, F. Fourcade, A. Amrane, F. Geneste, Reductive dechlorination of a chloroacetanilide herbicide in water by a Co complexsupported catalyst, Mol. Catal., 432 (2017) 8-14. 
[22] W. He, Y. Lou, E. Verlato, I. Soutrel, D. Floner, F. Fourcade, A. Amrane, M. Musiani, F. Geneste, Reductive dehalogenation of a chloroacetanilide herbicide in a flow electrochemical cell fitted with Ag-modified Ni foams, J. Chem. Technol. Biotechnol., 93 (2018) 1572-1578.

[23] Y.-Y. Lou, F. Geneste, I. Soutrel, A. Amrane, F. Fourcade, Alachlor dechlorination prior to an electro-Fenton process: Influence on the biodegradability of the treated solution, Sep. Purif. Technol., 232 (2020) 115936.

[24] Y.-Y. Lou, W. He, E. Verlato, M. Musiani, D. Floner, F. Fourcade, A. Amrane, C. Li, Z.-Q. Tian, O. Merdrignac-Conanec, Ni-coated graphite felt modified with Ag nanoparticles: A new electrode material for electro-reductive dechlorination, J. Electroanal. Chem., 849 (2019) 113357.

[25] E. Verlato, W. He, A. Amrane, S. Barison, D. Floner, F. Fourcade, F. Geneste, M. Musiani, R. Seraglia, Preparation of Silver-Modified Nickel Foams by Galvanic Displacement and Their Use as Cathodes for the Reductive Dechlorination of Herbicides, ChemElectroChem, 3 (2016) 2084-2092.

[26] S. Rondinini, E. Pargoletti, A. Vertova, A. Minguzzi, Hydrodehalogenation of Polychloromethanes on Silver-Based Gas Diffusion Electrodes, ChemElectroChem, 8 (2021) 1892-1898.

[27] L. Yang, Z. Chen, D. Cui, X. Luo, B. Liang, L. Yang, T. Liu, A. Wang, S. Luo, Ultrafine palladium nanoparticles supported on 3D self-supported Ni foam for cathodic dechlorination of florfenicol, Chem. Eng. J., 359 (2019) 894-901.

[28] F. Geneste, Catalytic electrochemical pre-treatment for the degradation of persistent organic pollutants, Curr. Opin. Electrochem., 11 (2018) 19-24.

[29] H. Shimakoshi, Y. Hisaeda, Electrochemistry and catalytic properties of vitamin B12 derivatives in nonaqueous media, Curr. Opin. Electrochem., 8 (2018) 24-30. 
[30] I. Dror, D. Baram, B. Berkowitz, Use of nanosized catalysts for transformation of chloro-organic pollutants, Environ. Sci. Technol., 39 (2005) 1283-1290.

[31] D.R. Burris, C.A. Delcomyn, M.H. Smith, A.L. Roberts, Reductive dechlorination of tetrachloroethylene and trichloroethylene catalyzed by vitamin B12 in homogeneous and heterogeneous systems, Environ. Sci. Technol., 30 (1996) 3047-3052.

[32] F. El-Athman, L. Adrian, M. Jekel, A. Putschew, Abiotic reductive deiodination of iodinated organic compounds and X-ray contrast media catalyzed by free corrinoids, Chemosphere, 221 (2019) 212-218.

[33] F. El-Athman, M. Jekel, A. Putschew, Reaction kinetics of corrinoid-mediated deiodination of iodinated X-ray contrast media and other iodinated organic compounds, Chemosphere, 234 (2019) 971-977.

[34] S. Kim, T. Park, W. Lee, Enhanced reductive dechlorination of tetrachloroethene by nano-sized mackinawite with cyanocobalamin in a highly alkaline condition, $\mathrm{J}$. Environ. Manage., 151 (2015) 378-385.

[35] W. Cheng, R.G. Compton, Quantifying the Electrocatalytic Turnover of Vitamin B12-Mediated Dehalogenation on Single Soft Nanoparticles, Angew. Chem. Int. Ed., 55 (2016) 2545-2549.

[36] M.C. Lagunas, D.S. Silvester, L. Aldous, R.G. Compton, The electrochemistry of vitamin B12 in ionic liquids and its use in the electrocatalytic reduction of vicinal dibromoalkanes, Electroanalysis, 18 (2006) 2263-2268.

[37] H. Shimakoshi, Z. Luo, T. Inaba, Y. Hisaeda, Electrolysis of trichloromethylated organic compounds under aerobic conditions catalyzed by the B 12 model complex for ester and amide formation, Dalton Trans., 45 (2016) 10173-10180.

[38] S.A. Stromeyer, K. Stumpf, A.M. Cook, T. Leisinger, Anaerobic degradation of tetrachloromethane by Acetobacterium woodii: separation of dechlorinative activities 
in cell extracts and roles for vitamin B12 and other factors, Biodegradation, 3 (1992) 113-123.

[39] J.G. Becker, D.L. Freedman, Use of Cyanocobalamin To Enhance Anaerobic Biodegradation of Chloroform, Environ. Sci. Technol., 28 (1994) 1942-1949.

[40] D. James, R. Cord-Ruwisch, D. Schleheck, M. Lee, M. Manefield, Cyanocobalamin enables activated sludge bacteria to dechlorinate hexachloro-1, 3butadiene to nonchlorinated gases, Biorem. J., 12 (2008) 177-184.

[41] F. Geneste, C. Moinet, Electrocatalytic oxidation of alcohols by a [Ru(tpy)(phen) $\left.\left(\mathrm{OH}_{2}\right)\right]^{2+}$-modified electrode, J. Electroanal. Chem., 594 (2006) 105-110. [42] O.A. Ashiru, J.P.G. Farr, Kinetics of reduction of silver complexes at a rotating disk electrode, J. Electrochem. Soc., 139 (1992) 2806-2810.

[43] I. Saidi, I. Soutrel, F. Fourcade, A. Amrane, D. Floner, N. Bellakhal, F. Geneste, Flow electrolysis on high surface electrode for biodegradability enhancement of sulfamethazine solutions, J. Electroanal. Chem., 707 (2013) 122-128.

[44] J.-M. Saveant, Elements of Molecular and Biomolecular Electrochemistry: An Electrochemical Approach to Electron Transfer Chemistry, Wiley-Interscience, New Jersey, 2006.

[45] T.J. Davies, C.E. Banks, B. Nuthakki, J.F. Rusling, R.R. France, J.D. Wadhawan, R.G. Compton, Surfactant-free emulsion electrosynthesis via power ultrasound: electrocatalytic formation of carbon-carbon bonds, Green Chem., 4 (2002) 570-577. [46] D. Lexa, J.M. Saveant, The electrochemistry of vitamin B12, Acc. Chem. Res., 16 (1983) 235-243.

[47] D. Lexa, J.M. Sayeant, J. Zickler, Electrochemistry of vitamin B12. 5. Cyanocobalamins, J. Am. Chem. Soc., 102 (1980) 2654-2663.

[48] L. Ngandu, D. Robin, A. El Kasmi, D. Lexa, Vitamin B12-transport protein 
interaction: electrochemistry of aquo-and glutathionyl-cobalamins adsorbed on carbon electrodes; role of the nucleotide chain, Inorg. Chim. Acta, 292 (1999) 204-212.

[49] T.F. Connors, J.V. Arena, J.F. Rusling, Electrocatalytic reduction of vicinal dibromides by vitamin B12, J. Phys. Chem., 92 (1988) 2810-2816.

[50] J.F. Rusling, C.L. Miaw, E.C. Couture, Electrocatalytic dehalogenation of $\alpha-$ haloacetic acids by vitamin B12, Inorg. Chem., 29 (1990) 2025-2027.

[51] J.E. Argueello, C. Costentin, S. Griveau, J.-M. Saveant, Role of Protonation and of Axial Ligands in the Reductive Dechlorination of Alkyl Chlorides by Vitamin B12 Complexes. Reductive Cleavage of Chloroacetonitrile by Co(I) Cobalamins and Cobinamides, J. Am. Chem. Soc., 127 (2005) 5049-5055.

[52] J.L. Kormos, M. Schulz, H.-P.E. Kohler, T.A. Ternes, Biotransformation of Selected Iodinated X-ray Contrast Media and Characterization of Microbial Transformation Pathways, Environ. Sci. Technol., 44 (2010) 4998-5007.

[53] F. Geneste, C. Moinet, S. Ababou-Girard, F. Solal, Covalent attachment of TEMPO onto a graphite felt electrode and application in electrocatalysis, New J. Chem., 29 (2005) 1520-1526. 